https://helda.helsinki.fi

\title{
A trust-focused model of leaders' fairness enactment
}

\section{Seppälä, Tuija}

2012-01

Seppälä , T , Pirttilä-Backman , A-M \& Lipsanen , J O 2012 , ' A trust-focused model of leaders' fairness enactment ' , Journal of Personnel Psychology , vol. 11 , no. 1 , pp. 20-30 . https://doi.org/10.1027/

http://hdl.handle.net/10138/234021

https://doi.org/10.1027/1866-5888/a000057

acceptedVersion

Downloaded from Helda, University of Helsinki institutional repository.

This is an electronic reprint of the original article.

This reprint may differ from the original in pagination and typographic detail.

Please cite the original version. 
Seppälä, T., Pirttilä-Backman, A-M., \& Lipsanen, J. O. (2012).

A trust-focused model of leaders' fairness enactment.

Journal of Personnel Psychology, 11(1): 20-30.

DOI: $10.1027 / 1866-5888 / a 000057$

A Trust-Focused Model of Leaders' Fairness Enactment 


\begin{abstract}
In this article, we present a trust-focused model for understanding leader's fairness enactment. The model suggests that leaders are motivated to act fairly to gain subordinates' trust, to show trust in their subordinates, to show that they are worth the subordinates' trust in them, and because they are willing to be vulnerable to the actions of cooperative subordinates. The mediating role of the leader's trust in the relationship between a subordinate's cooperation and the leader's fairness is also tested.
\end{abstract}

Keywords: leader fairness; trust in a subordinate; trust in a leader; being trusted, cooperation 
Fairness is part and parcel of ethical and efficient leadership (Tyler \& De Cremer, 2009). A number of studies have evidenced the beneficial effects of perceived fairness on employees' attitudinal and behavioral outcomes (e.g., Colquitt, Conlon, Wesson, Porter, \& Ng, 2001). Although fairness is an important factor in terms of organizational efficiency, many leaders fail to treat all of their subordinates fairly. Thus, it is important to know why leaders act fairly (e.g., Scott, Colquitt, \& Paddock, 2009).

In the previous literature, leaders' fairness enactment is explained by factors at different levels (e.g., Brebels, De Cremer, Van Dijke, \& Van Hiel, 2011; Schminke, Ambrose, \& Cropanzano, 2000; Scott, Colquitt, \& Zapata-Phelan, 2007). What seems to be missing from the ongoing discussion is a relational approach to a leader's fairness enactment. This is an evident lack as several theories (e.g., Lind \& Tyler, 1988; Tyler \& Blader, 2000; Tyler \& Lind, 1992) have emphasized the relational nature of fairness. In this paper, we suggest that leaders use fairness to build relationships with their subordinates, and on the other hand that the quality of that relationship influences leaders' motivation to act fairly.

Relational models that deal with responses to fairness have focused on variables such as pride, respect and identification (e.g., Tyler \& Blader, 2000). Pride refers to members' feelings about the status of their group, respect denotes members' feelings about their status within the group, and identification reflects individual's readiness to define him- or herself as a member of the group (e.g., Tyler \& Blader, 2000). Hence, these variables cover a groupmember's relational concerns with respect to the group but pride, respect or identification do not explicitly indicate the quality of the relationship between a leader and a group-member.

One such variable which assesses the quality of the relationship between a leader and a group-member, and which is involved in relational models that deal with the predictors of fairness judgements, is interpersonal trust (e.g., Tyler \& Lind, 1992). Although trust is not included in relational models that deal with responses to fairness (Tyler \& Blader, 2000), 
research shows that a group-member's trust in a leader accounts for the fact that fairness has an effect on outcomes such as cooperation (e.g., Dirks \& Ferrin, 2002). Thus, the opportunity to build a trusting relationship with a subordinate might motivate a leader's fairness enactment.

On the other hand, this motivation might be restricted by the subordinate's characteristics and behaviour. Previous studies have shown that the employee's characteristics and behaviours have an effect on the leader's fairness enactment but there is only one study that has tested a reason for that effect. Scott et al. (2007) found that the leader's positive sentiments towards a subordinate mediated the positive association between the subordinate's charisma and the leader's interpersonal fairness. Thus, more studies are needed to find out the relational mechanisms that account for this effect. In this paper, we focus on the mediating role of a leader's trust in the relationship between a subordinate's cooperation and a leader's fairness enactment. Trust might be a relevant relational factor in the leader's fairness as it implies that the relationship between a leader and a subordinate is cooperative rather than competitive or abusive (e.g., Lind, 2001).

In this paper, we present a trust-focused model of the leader's fairness enactment. The model integrates the leader's perspective on trust and fairness to the subordinate's perspective on these phenomena. This integration supplements an understanding of the relationship between fairness and trust in the leader-subordinate relationship. In addition, this paper contributes to the growing literature on fairness as a dependent variable by suggesting trustrelated mechanisms through which the employee's behavior is related to leader fairness. Beside the theoretical implications, this study informs practitioners on factors that determine the leader's fairness. The suggested model is presented in Figure 1 and the content of the model is described in what follows. The mediating role of the leader's trust in the relationship between a subordinate's cooperation and the leader's fairness is also tested. 
Figure 1

\section{A Trust-Focused Model of Leaders' Fairness Enactment}

The model depicted in Figure 1 considers the interaction between a subordinate's cooperation and a leader's fairness enactment and it focuses on the role of trust as a relational construct in this interaction. The model suggests four trust-related mechanisms which motivate leaders' fairness: fairness is a tool for begetting the subordinate's trust in the leader, fairness is a tool for showing that the subordinate is trusted, fairness is an outcome of the leader's trust in the subordinate, and fairness is a tool for reciprocating the trust received from a subordinate. The model also suggests that the subordinate's trust in the leader and the subordinate's feeling of being trusted motivate cooperation. Moreover, the cooperation is suggested to predict both the leader's trust in the subordinate and the leader's feelings of being trusted by the subordinate. The model is presented in the following.

\section{Leaders' Fairness and Subordinates' Trust in the Leader}

Justice concerns are generally differentiated as distributive, procedural, and interactional justice. Distributive justice refers to the perceived fairness of the outcomes (e.g., rewards, work duties) in proportion to performance inputs (e.g., Adams, 1965; Greenberg, 1996; Leventhal, 1976). Procedural justice captures the perceived fairness of the procedures used (e.g., consistency, voice) in the decision-making process regarding the outcomes (Folger \& Cropanzano, 1998; Leventhal, 1980; Thibaut \& Walker, 1975). Interactional justice refers to the dignity and respect with which a person is treated in the process of decision making (Bies \& Moag, 1986). Previous studies on the leader's fairness enactment have focused only on interactional fairness (e.g., Scott et al., 2007). This is a gap in the literature because leaders 
also have an influence on perceived distributive and procedural fairness (e.g., van Knippenberg, De Cremer, \& van Knippenberg, 2007).

The literature on fairness suggests several reasons why fairness matters (e.g., Blader \& Tyler, 2005). According to the fairness heuristic theory (e.g., Lind, 2001), fairness offers heuristic information on another party's trustworthiness. Trust, in turn, matters because it is a basis for cooperation. Cooperation and identification with organizations improve employees' capacities to attain goals and outcomes and to enhance their self-identity. On the other hand, psychological engagement and investment in an organization mean that an employee is vulnerable to rejection and exploitation. To resolve this "fundamental social dilemma," the fairness heuristic theory proposes that individuals use fairness perceptions (Lind, 2001): fair leaders are trusted to not take advantage of cooperative actions. On the other hand, an unfair leader implies that rejection and exploitation are likely, and self-serving rather than cooperative behavior is considered to be reasonable.

If the perspective is directed away from the receiver and towards the actor, this suggests that by acting fairly, leaders are able to earn their subordinates' trust and to show that it is worth identifying and cooperating with the organization. Indeed, empirical literature shows that perceived fairness predicts the subordinate's trust in the leader (e.g., Ambrose \& Schminke, 2003) and that trust predicts cooperative behaviors and attitudes (e.g., Mayer \& Gavin, 2005). Moreover, studies show that trust in the leader mediates the positive relationship between fairness and cooperation (e.g., Dirks \& Ferrin, 2002; van Dijke, De Cremer, \& Mayer, 2010). Thus, to initiate and maintain the subordinate's trust and consequent cooperation, leaders should be motivated to act fairly.

\section{Leaders' Fairness and Subordinates Being Trusted}

Fairness might also be a tool for showing that the subordinate is trusted. As relational models of justice state (see e.g., Tyler \& Blader, 2000), fairness also matters because it 
communicates to an employee the quality of the relationship with the organizational authorities and the subordinate's position in the organization. Again, if the actor's perspective is taken, this suggests that by acting fairly the leader is able to communicate to the subordinate that he or she is a trusted member of the organization and that the organization is worth identifying and cooperating with. For example, Lau, Liu and Fu (2007) found that moral leadership, which captured fairness components, informed employees that they were trusted.

An employee's feeling of being trusted is also of interest to leaders as it predicts the employee's cooperative behaviors (e.g., Brower, Lester, Korsgaard, \& Dineen, 2009; Salamon \& Robinson, 2008). Salamon and Robinson (2008), for example, found that the collective feeling of being trusted predicted organizational performance because of the responsibility norm; trusted employees felt that their responsibility was to help the organization to achieve its goals. Experimental studies (e.g., Malhotra, 2004) have also shown that the more people feel that they are trusted and benefitted the more they feel obliged to reciprocate. Brower et al., (2008) suggest that in respect of employee cooperation, the role of being trusted is even more important than the role of trust in a leader. Thus, leaders should be motivated to act fairly to make subordinates feel that they are trusted and willing to cooperate.

\section{Subordinates' Cooperation, Leaders' Trust in Subordinates and Leaders' Fairness}

An important question is whether leaders are willing or able to treat all of their subordinates fairly and to build a trusting relationship with all them. Previous studies seem to suggest that this is not the case. For example Korsgaard, Roberson and Rymph (1998) found that in a performance appraisal situation, managers treated employees more fairly who communicated assertively. Gilliland and Schepers (2003) reported that managers behaved in a more involved way with layoff victims who had substantially contributed to the success of 
the manager's division because they were perceived to be more deserving of care. Scott et al. (2007) found that charismatic employees were treated interpersonally (i.e., respect and propriety) more fairly because their charisma enhanced positive and reduced negative sentiments. These studies suggest that leaders differentiate between subordinates, and subordinates have an influence on a leader's fairness enactment.

Scott et al. (2009) have more systematically modeled managerial motivation which arises from interactions with subordinates. They have presented an actor-focused model of managerial justice rule adherence and violation. The model proposes that managers are motivated to adhere to or violate justice rules for cognitive and affective reasons. In terms of cognitive reasons, managers are suggested to pursue valued outcomes, such as the controlling of subordinates' behaviors, impression management and maintaining balance in their justice scale, by giving the subordinates what they are perceived to deserve. With respect to affective reasons, managers are proposed to treat those subordinates fairly who elicit positive affect because fairness is a way to maintain this positive affect. On the other hand, subordinates who elicit negative affect are mistreated because mistreatment is believed to reduce negative feelings.

Moreover, the model proposes that actual justice rule adherence or violation is dependent on the amount of discretion related to different types of justice. Thus, justice types are situated on a continuum such that discretion is lowest with respect to distributive and highest with respect to interpersonal actions, whereas procedural and information actions lie between these two. Finally, the model proposes that managers appraise their own actions against societal norms, and their own goals and subordinates' reactions, and consequently feel pride or guilt. Guilt-engendering actions are avoided in the future, while pride-engendering actions are continued. 
Although the actor-focused model covers a great many justice motivating factors, it can be seen that relational goals are missing. As mentioned earlier, we consider that fairness is also a way to maintain or build a trusting relationship with subordinates. However, it is also suggested that even though fairness might be an important goal for most leaders, it is hard for leaders to act fairly and earn trust from less trusted subordinates; fairness enactment requires a willingness to be vulnerable to the actions of the subordinate (i.e. trust). We present some examples to illustrate this.

Low trust is found to intensify monitoring (e.g., Mayer \& Gavin, 2005). Monitoring, in turn, is associated with more negative and coercive communication (Amick \& Smith, 1992), which arouses feelings of disrespect within the monitored. The less trusted are also found to receive less information than the trusted because they are thought to use it for harmful purposes (e.g., Mayer et al., 1995). Moreover, trusted employees are given more control in decision-making, whereas leaders are found to emphasize their authority position and tighten up control with less trusted subordinates (e.g., Georgesen \& Harrin, 2006). The subordinate might perceive this controlling as unfair because procedures are perceived to be fair to the extent the perceiver feels that he or she has control over the decision-making process and the outcomes related to him or her (e.g., Thibaut \& Walker, 1975).

Further, poorly performing employees receive duties with lower responsibility and taskrelated autonomy because they are not trusted to cope with demanding duties (Mayer et al., 1995). These lower-quality tasks are associated with poorer salaries, lower social status and do not fulfill a need for a positive sense of self-esteem (e.g., Cropanzano \& Ambrose, 2001). In the eyes of the leader, the equity rule is followed if well-performing employees receive higher quality duties and poorly-performing employees are delegated lower quality duties. However, employees' performance ratings are found to be more optimistic than the supervisor's or peer ratings because of egocentric bias (Harris \& Schaubroeck, 1988). Thus, it 
is possible that subordinates who receive lower-quality duties think that they deserve better and perceive work-duties distribution as less fair than better-performing employees.

As the presented examples suggest, it is hard for leaders to be fair in the eyes of the less trusted subordinates. Ultimately, fairness is to quite some extent about giving up control to employees: fairness means opportunities to express one's views, appeal against decisions and receive information. Without trust it is hard for leaders to engage these fairness-enhancing actions. Subordinates, in turn, are suggested to evince trustworthiness and earn their leader's trust by cooperative actions such as in-role performance and organizational citizenship behaviors (Brower, Schoorman, \& Tan, 2000). Thus, the leader should be motivated to act fairly when the subordinate's behavior implies that he or she can be trusted.

Employees' cooperation might also communicate to the leader that he or she is trusted to act fairly and reciprocally (see also Ferrin, Bligh, \& Kohles, 2007). By cooperating, the subordinate makes him- or herself vulnerable to the actions of the leader. The leader might perceive that this trust placed in him or her and feels obligated to reciprocate this trust by acting fairly. Thus, the leader's willingness to be worthy of the trust placed in him or her motivates fairness enactment. However, we have found no studies which explore the motivating role of the leader's feelings of being trusted.

Part of our model already has strong empirical support from previous research: trust in the leader accounts for the positive relationship between fairness and cooperation. However, we do not know whether subordinates' cooperative behaviors and the leader's distributive, procedural and interactional fairness enactment are related, and whether the leader's trust in a subordinate accounts for the possible positive association. To offer support for this part of our model, we conducted a study in an organizational context. Other untested parts of the model are further handled in the discussion section. Based on our model, the hypotheses were as follows: 
Hypothesis 1: The subordinate's cooperative behaviors are positively related to the supervisor's distributive, procedural and interactional fairness.

Hypothesis 2: The supervisor's trust in the subordinate mediates the positive relationship of the subordinate's cooperative behaviors on the subordinate's perceptions of distributive, procedural and interactional fairness.

\section{Study}

\section{Method}

Sample and Procedures. Employees and their immediate supervisors in two Finnish organizations participated in a survey. ${ }^{1}$ One of the organizations was a social-service provider and the other was a restaurant chain. Altogether 189 employees $(66 \%)$ and 39 supervisors (98\%) responded. We excluded responses with missing values, and the final sample consisted of 174 employees $(61 \%)$ nested within $35(88 \%)$ supervisors. Almost half of the respondents (99 employees and 17 supervisors) represented the social-service provider organization and the other half (75 employees and 18 supervisors) was from the restaurant organization. The average number of respondents per unit was 7.9 employees (varying from 1 to 16; SD 4.3). On average, the employees were 38.6 years old $(S D=10.8)$, they had worked for 4.8 years $(\mathrm{SD}=5.8)$ under their present supervisor, and the majority of employees were female $(76 \%)$. The average age of the supervisor was $43.7(\mathrm{SD}=10.8)$ and $74 \%$ of them were female. Nonrespondents did not differ from respondents with respect to age, gender or tenure.

Measures. All the measures and items are presented in Appendix I. Employees rated their immediate supervisors on fairness and supervisors rated their subordinates on trust and cooperation. Employees' cooperative behaviors were measured with three scales which focused on in-role performance and organizational citizenship behaviors. In-role performance, helping and compliance were selected because they cover the three dimensions

\footnotetext{
${ }^{1}$ Some of the results are published elsewhere (Seppälä, Lipponen, Pirttilä-Backman, \& Lipsanen, (in press). Reciprocity of trust in the supervisor-subordinate relationship: The mediating role of autonomy and the sense of power. European Journal of Work and Organizational Psychology. doi: 10.1080/1359432X.2010.507353)
} 
of trustworthiness. According to Mayer et al.'s (1995) integrative model of organizational trust, supervisor trust in the subordinate is based on perceptions of the subordinate's trustworthiness, which consists of ability, benevolence, and integrity. Ability refers to "skills, competences, and characteristics that enable a party to have influence within some specific domain", benevolence is the employee's "desire to do good to the trustor" and integrity captures "the trustor's perception that the trustee adheres to a set of principles that the trustor finds acceptable" (Mayer et al, 1995, p. 717-719). Thus, performance implies ability, helping refers to benevolence, and compliance indicates integrity.

The scales consisted of three items which were rated on a seven-point scale $(1=$ very poorly, $7=$ very well $).$ The helping scale was taken from Van Dyne and LePine $(1998)(\alpha=$ .92, e.g., "This particular employee assists others in this unit with their work for the benefit of the group"). Compliance captured acceptance and adherence of the work unit's rules and regulations, and it was invented for this study $(\alpha=.66$, e.g., "This particular employee follows working-hour regulations with exactness"). Performance ratings covered the quantity and quality of the work and the amount of effort put into it and it was based on Williams and Anderson's (1991) measure ( $\alpha=.78$, e.g., "This particular employee meets the qualitative expectations of his/her work").

Supervisor trust in a subordinate was measured with four items. Three items were taken from Mayer and Davis's (1999) scale ${ }^{2}$ (e.g., "I would be comfortable giving this particular employee a task or problem that was critical to me, even if I could not monitor his/her actions"). A fourth item ("I trust him/her as an employee") was developed for this research. The items were rated on a five-point scale $(1=$ strongly disagree, $5=$ strongly agree $)$. The scale showed good internal consistency $(\alpha=.87)$.

\footnotetext{
${ }^{2}$ Mayer and Davis's (1999) trust scale includes four items. One of the items ("I would be willing to let this particular subordinate have complete control over my future in this unit") was not used in this study because we considered that it did not represent the leader's perspective well.
} 
Subordinates rated their supervisor on three dimensions of fairness. All the items were rated on a five-point scale ( $1=$ strongly disagree, $5=$ strongly agree $)$. The distributive justice scale consisted of seven items indicating perceived fairness of the work-duties distribution. The scale was taken from Lipponen and Wisse (2010) $(\alpha=.94$, e.g., "The decisions my immediate supervisor makes concerning the distribution of work are fair in relation to others doing a similar job"). Procedural justice was measured on a seven-item scale indicating the perceived quality of the decision-making procedures followed by the supervisor (e.g., "Everyone who is affected by the decision has a chance to voice his or her opinion"). The items were taken from Moorman's (1991) scale, and it showed high internal consistency ( $\alpha=$ .90). Interactional justice was measured on a five-item scale indicating the perceived quality of the treatment given by the supervisor. The items were taken from Moorman's (1991) scale (e.g., "My supervisor shows concern for our rights as employees"), and it showed high internal consistency $(\alpha=.94)$.

Analyses. First we conducted two confirmatory factor analyses to confirm the empirical distinctiveness of supervisor-rated variables and three fairness components rated by employees. The suggested four-factor model for supervisor-rated variables $\left(\chi^{2}=107.88, \mathrm{df}=\right.$ $54, \mathrm{CFI}=0.96, \mathrm{TLI}=0.92, \mathrm{RMSEA}=0.076)$ fitted data significantly better than the other possible models. With respect to fairness components, the suggested three-factor model $\left(\chi^{2}=\right.$ 376.25, $\mathrm{df}=157, \mathrm{CFI}=0.95, \mathrm{TLI}=0.93, \mathrm{RMSEA}=0.079)$ fitted the data significantly better than the other possible models. Thus, these analyses showed that our measurement model was satisfactory. Analyses are presented in Appendix II.

Because employees were nested in the units and supervisors rated multiple subordinates, we examined the data for unit level effects (Kenny \& Judd, 1986). The results showed that the total variance explained by unit membership was: trust $34.7 \%$; distributive justice $8.5 \%$; procedural justice $27.0 \%$, and interactional justice $32.4 \%$. Because of this great variation 
among units, the analyses were conducted using the two-level random intercept structural equation model with the MPLUS version 5.2 software (Muthen \& Muthen, 1998-2007; Preacher, Zyphur, \& Zhang, 2010). We also tested the two-level random slope model, which did not improve the model, so only results for random intercept structural model are reported. We used sums of observed variables in the primary analyses to maintain an adequate sample size of parameter ratio (Bollen, 1989).

Results. The scale means, standard deviations, inter-correlations, and reliabilities are presented in Table 1. The correlation matrix showed that all the independent variables correlated positively with the suggested mediator, which in turn correlated positively with the three outcome variables. Moreover, helping correlated with interactional fairness, compliance correlated with procedural fairness, and performance correlated with distributive fairness. These results offered preliminary support for our hypotheses to the extent that a specific cooperation dimension was only related to a specific fairness dimension.

Table 1

To test the hypotheses in detail, we first estimated the baseline model including only random intercepts and then the only directs model which included paths from a specific cooperation dimension to each fairness dimension. Hypothesis 1 suggested that helping, compliance and performance would be positively related to the supervisor's distributive, procedural and interactional fairness. Analyses showed that helping was related to interactional $(\beta=.17 ; \mathrm{SE}=.07, p<.05)$, procedural $(\beta=.15 ; \mathrm{SE}=.06, p<.01)$ and distributive fairness $(\beta=.10 ; \mathrm{SE}=.05, p<.05)$. Further, compliance was related to interactional $(\beta=.17 ; \mathrm{SE}=.08, p<.05)$ and procedural $(\beta=.20 ; \mathrm{SE}=.07, p<.01)$ but not to 
distributive fairness $(\beta=.13 ; \mathrm{SE}=.08, p>.05)$. Finally, performance was only related to distributive fairness $(\beta=.19 ; \mathrm{SE}=.08, p<.05)$ but not to procedural $(\beta=.10 ; \mathrm{SE}=.09, p>$ $.05)$ or to interactional fairness $(\beta=.14 ; \mathrm{SE}=.09, p>.05)$. Thus, Hypothesis 1 was supported in the sense that performance was related only to distributive fairness, helping was related to all the fairness components, and compliance was related to procedural and interactional fairness.

To test hypothesis 2 , which suggested that trust mediates the positive relationship between the subordinate's helping, compliance and performance on three justice components, we first estimated the no directs model. The model included paths from each independent variable to the suggested mediator and paths from the mediator to each dependent variable. The model showed a good fit with the data as shown in Table 2. Analyses showed that helping $(\beta=.09 ; \mathrm{SE}=.04, p<.01)$, compliance $(\beta=.15 ; \mathrm{SE}=.07, p<.05)$ and performance $(\beta=.38 ; \mathrm{SE}=.06, p<.001)$ were all positively related to supervisor trust and that supervisor trust was positively related to distributive $(\beta=.29 ; \mathrm{SE}=.11, p<.01)$, procedural $(\beta=.25 ; \mathrm{SE}$ $=.08, p<.01)$ and interactional $(\beta=.36 ; \mathrm{SE}=.08, p<.001)$ fairness. These results proved that all the independent variables were related to the suggested mediator, which in turn was related to all the suggested outcome variables.

We then estimated six additional models for the fully mediated model. Each of these models included the mediator and a specific direct path found while testing Hypothesis 1 . As shown in Table 2, none of these alternative models fitted the data better than the hypothesized and more parsimonious fully mediated model. Moreover, the direct paths were no longer significant: from helping to interactional $(\beta=.03 ; \mathrm{SE}=.05, p>.05)$, procedural $(\beta=.02 ; \mathrm{SE}$ $=.04, p>.05)$ and distributive fairness $(\beta=-.01 ; \mathrm{SE}=.04, p>.05)$; from compliance to procedural $(\beta=.07 ; \mathrm{SE}=.07, p>.05)$ and interactional fairness $(\beta=-.03 ; \mathrm{SE}=.07, p>.05$ and from performance to distributive fairness $(\beta=.12 ; \mathrm{SE}=.08, p>.05)$. Confidence 
intervals for mediated effects were estimated by standard method for multilevel data (Preacher et al., 2010). Helping had a significant mediated effect on interactional (.03; SE = $.02, p<.05)$ and distributive fairness $(.03 ; \mathrm{SE}=.02, p<.05)$ but not on procedural fairness $(.02 ; \mathrm{SE}=.01, p>.05)$. Performance had a significant mediated effect on interactional fairness $(.11 ; \mathrm{SE}=.05, p<.05)$. Mediated effect of compliance on procedural $(.04 ; \mathrm{SE}=.03$, $\mathrm{p}>.05)$ and interactional fairness $(.05 ; \mathrm{SE}=.04, p>.05)$ proved non-significant. Thus hypothesis two was supported in a sense that the leader's trust mediated the specific effect of performance on distributive fairness and the effect of helping on interactional and distributive fairness. In multilevel analysis only supervisor trust had a significant level-two variance component in the final model.

Table 2

\section{Study-related discussion}

This article aimed to increase understanding about the subordinate's role in supervisor fairness enactment. We introduced a trust-focused model of the leader fairness enactment which integrates the leader's and the subordinate's perspectives on fairness and trust. The model suggested four trust-related mechanisms which motivate leader fairness. One of these mechanisms was also tested. We found that the leader's trust in a subordinate accounts for the positive relationship between the subordinate's cooperation and the leader's fairness. More precisely, we found that the supervisor's trust mediated the association of a specific cooperation dimension on some fairness dimensions only. This finding seems to be in line with the general notion according to which trust is not a generic belief but a trustor trusts a trustee in a specific respect and behaves accordingly (e.g., Mayer et al., 1995). Our results 
suggest that once trust is based on in-role performance, the trustor is willing to be vulnerable to the trustee's future in-role-related actions and thus treats this particular subordinate favorably in work-duties distribution. However, in-role performance does not indicate whether the subordinate is, for instance, willing to keep confidential information to him- or herself or how she or he interacts with other people in day-to-day encounters. Hence, performance-based trust is unrelated to procedural or interactional fairness. On the other hand, helping was related through trust to distributive and interpersonal fairness. Helping is found to be positively related to overall performance evaluation (e.g., Van Dyne \& LePine, 1998). Thus it is reasonable to find also that helping had an effect on distributive fairness. Voluntarily helping employees are also trusted to want what is good for the organization and thus they are perceived as deserving respectful treatment.

Our findings also supplement Scott et al.'s (2007) study, which is the only study that has actually tested reasons for the positive relationship between a subordinate-related factor and a leader's fairness enactment. Their findings suggest that leaders are motivated to treat subordinates interpersonally fairly to maintain positive sentiments elicited by the charismatic subordinates. Our findings suggest that a subordinate's cooperation is related to a leader's cooperation (i.e. fairness) also because the subordinate's cooperation enhances the leader's willingness to be vulnerable to the actions of the subordinate. Our study also suggests that it is worth researching the subordinate's role not only in interactional fairness, as previous studies have done (e.g., Scott et al., 2007) but also in distributive and procedural fairness. However, this study also has some limitations. Even though the study was conducted in a real-world context and the independent and dependent variables were rated by separate sources, the study failed to provide conclusive causal evidence. Thus, experimental or longitudinal designs are needed to further test the suggested mediation. 
In practical terms, the study suggests that it is hard for leaders to treat the less cooperative subordinates fairly because of low trust. Leaders might be able to turn this negative reciprocity into positive reciprocity by initiating trust within uncooperative subordinates and by showing that they are trusted to do their best, in which case these subordinates should become more cooperative (e.g., Brower et al., 2009). This requires extra efforts in fairness and presumes that the leaders are aware of the motivators and consequences of their behavior. On the other hand, this study suggests that subordinates are able to influence the treatment they receive by doing their best in their work and voluntarily participating in helping others. Employees should be made aware that their own contribution also matters because employees might justly expect that it is the leader's responsibility to treat all the employees equally (e.g., Folger \& Cropanzano, 1998).

\section{Model-related discussion}

The introduced model presents a more holistic perspective in the fairness-trust relationship than the previous literature. In addition, this trust-focused model offers a relational perspective on fairness enactment by suggesting that fairness is a way to build and maintain a trusting relationship, which should be a goal of efficient and ethical leadership. Fairness is a relational construct in the sense that it communicates to the receiver where to stand with the actor (e.g., Lind, 2001) and where the actor stands with the receiver (e.g., Tyler \& Blader, 2000). Thus, the model offers an important perspective which has not been acknowledged in the existing models on leaders' justice motivation (see Scott et al., 2009). Moreover, the introduced model suggests that traditionally receiver-focused models of fairness (e.g., Lind, 2001; Tyler \& Blader, 2000) can be used to explain the actor's motivation to behave fairly. If the perspective is turned from the receiver to the actor, as we did in our model, it suggests that leaders might be motivated to act fairly because fairness 
communicates to the subordinate that the leader can be trusted and that the subordinate is trusted by the leader.

The presented model offers several ideas to be tested in the future. We consider that in particular being trusted deserves more attention as it seems to have motivating forces which might count even more than trust (e.g., Brower et al., 2008; Salamon \& Robinson, 2008). Research could provide evidence about when the leader feels he or she is trusted by subordinates and whether this feeling motivates leader's fairness. Research could also test the interaction between the leader being trusted and the leader's trust in a subordinate. It could be that if the leader trusts in a subordinate but feels that this trust is not mutual, the trusting leader makes extra efforts to be fair to initiate the subordinate's trust. Research is also needed to show whether fairness accounts for the leader's and the subordinate's trust in each other. Finally, future studies could also integrate Scott et al.'s (2009) idea of discretion in the model presented here. Scott et al. (2009) suggests that managerial discretion to adhere to or violate justice rules varies between justice components. It is possible that the relationship between the leader's trust and different fairness components varies in strength depending on the leader's discretion in a particular context.

To conclude, this article suggests that leaders' fairness enactment is motivated by their willingness to increase the trust placed in them, by willingness to show that the subordinate is trusted, by willingness to be vulnerable to the actions of a subordinate and by willingness to be worthy of shown trust. It is hoped that the introduced model encourages researchers to focus on factors that motivate supervisor justice, to re-examine previous findings, and examine untested parts of the introduced model. 


\section{References}

Adams, J. (1965). Inequity in social exchange. In L. Berkowitz (Ed.), Advances in experimental social psychology, pp. 267-299. New York: Academic Press.

Ambrose, M., \& Schminke, M. (2003). Organizational structure as a moderator of the relationship between procedural justice, interactional justice, perceived organizational support, and supervisor support. Journal of Applied Psychology, 88, 295-305. doi: $10.1037 / 0021-9010.88 .2 .295$

Amic, B., \& Smith, M. (1992). Stress, computer-based work monitoring, and measurement systems: A conceptual overview. Applied Ergonomics, 23, 6-16.

Baron, R., \& Kenny, D. (1986). The moderator-mediator variable distinction in social psychological research: conceptual, strategic, and statistical considerations. Journal of Personality and Social Psychology, 51, 1173-82.

Bies, R., \& Moag, J. (1986). Interactional justice: Communication criteria of fairness. In R. Lewis, B. Sheppard, \& M. Bazerman (Eds.), Research on negotiations in organizations (pp. 43-55). Greenwich, CT: JAI Press.

Blader, S., \& Tyler, T. (2005). How can theories of organizational justice explain the effects of fairness? In J. Greenberg \& J. Colquitt (Eds.), Handbook of organizational justice (pp. 329-354). Mahwah: LEA.

Bollen, K. (1989). Structural equations with latent variables. New York: Wiley.

Brebels, L., De Cremer, D., Van Dijke, M., \& Van Hiel, A. (2011). Fairness as social responsibility: A moral self-regulation account of procedural justice enactment. British Journal of Management, 22, 47-58. doi: 10.1111/j.1467-8551.2010.00715.x

Brower, H., Lester, S., Korsgaard, M., \& Dineen, B. (2009). A closer look at trust between managers and subordinates: Understanding the effects of both trusting and being trusted 
on subordinate outcomes. Journal of Management, 35, 327-348. doi: $10.1177 / 0149206307312511$

Brower, H., Schoorman, F., \& Tan, H. (2000). A model of relational leadership: The integration of trust and leader-member exchange. Leadership Quarterly, 11, 227-250.

Colquitt, J., Conlon, M., Wesson, C., Porter, C., \& Ng, K. (2001). Justice at the millennium: A meta-analytic review of 25 years of organizational justice research. Journal of Applied Psychology, 86, 425-445.

Cropanzano, R., \& Ambrose, M. (2001). Procedural and distributive justice are more similar than you think: A monistic perspective and a research agenda. In J. Greenberg \& R. Cropanzano (Eds.), Advances in organizational justice (pp. 119-151). Stanford: Stanford University Press.

Dirks, K., \& Ferrin, D. (2002). Trust in leadership: Meta-analytic findings and implications for research and practice. Journal of Applied Psychology, 87, 611-628. doi: $10.1037 / / 0021-9010.87 .4 .611$

Ferrin, D., Bligh, M., \& Kohles, J. (2007). Can I trust you to trust me? A theory of trust, monitoring, and cooperation in interpersonal and intergroup relationships. Group and Organization Management, 32, 465-499. doi: 10.1177/1059601106293960

Folger, R., \& Cropanzano, R. (1998). Organizational justice and human resource management. Thousand Oaks, CA: Sage.

Georgesen, J., \& Harris, M. (2006). Holding onto power: Effects of powerholders' positional instability and expectancies on interactions with subordinates. European Journal of Social Psychology, 36, 451-468. doi: 10.1002/ejsp.352

Gilliland, S., \& Schepers, D. (2003). Why we do the things we do: A discussion and analysis of determinants of just treatment in layoff implementation decisions. Human Resource Management Review, 13, 59-83. doi: 10.1016/S1053-4822(02)00099-2 
Greenberg, J. (1996). The quest for justice on the job. Thousand Oaks, CA: Sage.

Harris, M., \& Schaubroeck, J. (1988). A meta-analysis of self-supervisor, self-peer, and peersupervisor ratings. Personnel Psychology, 41, 43-62.

Kenny, D. A., \& Judd, C. M. (1986). Consequences of violating the independence assumption in analysis of variance. Psychological Bulletin, 99, 422-431.

Korsgaard, M., Roberson, L., \& Rymph, R. (1998). What motivates fairness? The role of subordinate assertive behavior on manager's interactional fairness. Journal of Applied Psychology, 83, 731-744.

Lau, D., Liu, J., \& Fu, P. (2007). Feeling trusted by business leaders in China: Antecedents and the mediating role of value congruence. Asia Pacific Journal of Management, 24, 324-340. doi: 10.1007/s 10490-006-9026-z

Leventhal, G. (1976). The distribution of rewards and resources in groups and organizations. In L. Berkowitz \& W. Walster (Eds.), Advances in experimental social psychology (pp. 91-131). New York: Academic Press.

Leventhal, G. (1980). What should be done with equity theory? New approaches to the study of fairness in social relationships. In K. Gergen, M. Greenberg, \& R. Willis (Eds.), Social exchange: Advances in theory and research (pp. 27-55). New York: Plenum Press.

Lind, A. (2001). Fairness heuristic theory: Justice judgements as pivotal cognitions in organizational relations. In J. Greenberg \& R. Cropanzano, Advances in organizational justice (pp.56-88). CA: Stanford University Press.

Lind, A., \& Tyler, T. (1988). The social psychology of procedural justice. New York: Plenum Press.

Lipponen, J., \& Wisse, B. (2010). Shared perceptions of perceived justice as a predictor of externally rated departmental level academic performance. Journal of Organizational and Occupational Psychology, 83, 1065-1074. doi: 10.1348/09631709X479727 
Malhotra, D. (2004). Trust and reciprocity decisions: The differing perspectives of trustors and trusted parties. Organizational Behavior and Human Decision Processes, 94, 61-73. doi: 10.1016/j.obhdp.2004.03.001

Mayer, R., \& Davis, J. (1999). The effect of the performance appraisal system on trust for management: A field quasi-experiment. Journal of Applied Psychology, 84, 123-136.

Mayer, R., Davis, J., \& Schoorman, F. (1995). An Integrative model of organizational trust. Academy of Management Review, 20, 709-734.

Mayer, R., \& Gavin, M. (2005). Trust in management and performance: Who minds the shop while the employees watch the boss? Academy of Management Journal, 48, 874-888.

Moorman, R. (1991). Relationship between organizational justice and organizational citizenship behaviors: Do fairness perceptions influence employee citizenship? Journal of Applied Psychology, 76, 845-855.

Muthén, L. \& Muthén, B. (1998-2007). MPLUS user's guide (5th ed.). Los Angeles, CA: Authors.

Preacher, K., Zyphur, M., \& Zhang, Z. (2010). A general multilevel SEM framework for assessing multilevel mediation. Psychological Methods, 15, 209-233. doi: $1010.1037 / \mathrm{a} 0020141$

Salamon, S., \& Robinson, S. (2008). Trust that binds: The impact of collective felt trust on organizational performance. Journal of Applied Psychology, 93, 593-601. doi: $10.1037 / 0021-9010.93 .3 .593$

Schminke, M., Ambrose, M., \& Cropanzano, R. (2000). The effect of organizational structure on perceptions of procedural fairness. Journal of Applied Psychology, 85, 294-304.

Scott, B., Colquitt, J., \& Paddock, E. (2009). An actor-focused model of justice rule adherence and violation: The role of managerial motives and discretion. Journal of Applied Psychology, 94, 756-769. doi: 10.1037/a0015712 
Scott, B., Colquitt, J., \& Zapata-Phelan, C. (2007). Justice as a dependent variable: Subordinate charisma as a predictor of interpersonal and informational justice perceptions. Journal of Applied Psychology, 92, 1597-1609. doi: 10.1037/00219010.92.6.1597

Thibaut, J., \& Walker, L. (1975). Procedural justice: A psychological analysis. Hillsdale, NJ: LEA.

Tyler, T., \& Blader, S. (2000). Cooperation in groups. Procedural justice, social identity, and behavioral engagement. Philadelphia: Psychology Press.

Tyler, T., \& De Cremer, D. (2009). Ethics and rule adherence in groups. In D. De Cremer (ed.), Psychological perspectives on ethical behavior and decision making. Greenwich, CT: Information Age.

Tyler, T., \& Lind, A. (1992). A relational model of authority in groups. In M. Zanna (Ed.), Advances in experimental social psychology (pp. 115-191). San Diego: Academic Press.

Van Dijke, M., De Cremer, D., \& Mayer, D. (2010). The role of authority power in explaining procedural fairness effects. Journal of Applied Psychology, 95, 488-502. doi: $10.1037 / \mathrm{a} 0018921$

Van Dyne, L., \& LePine, J. (1998). Helping and voice extra-role behaviors: Evidence of construct and predictive validity. Academy of Management Journal, 41, 108-119.

van Knippenberg, D., De Cremer, D., \& van Knippenberg, B. (2007). Leadership and fairness: The state of the art. European Journal of Work and Organizational Psychology, 16, 113-140. doi: 10.1080/13594320701275833

Williams, L., \& Anderson, S. (1991). Job satisfaction and organizational commitment as predictors of organizational citizenship and in-role behaviors. Journal of Management, $17,601-617$. 
Figure 1

A Trust-Focus Model of Leader Fairness Enactment

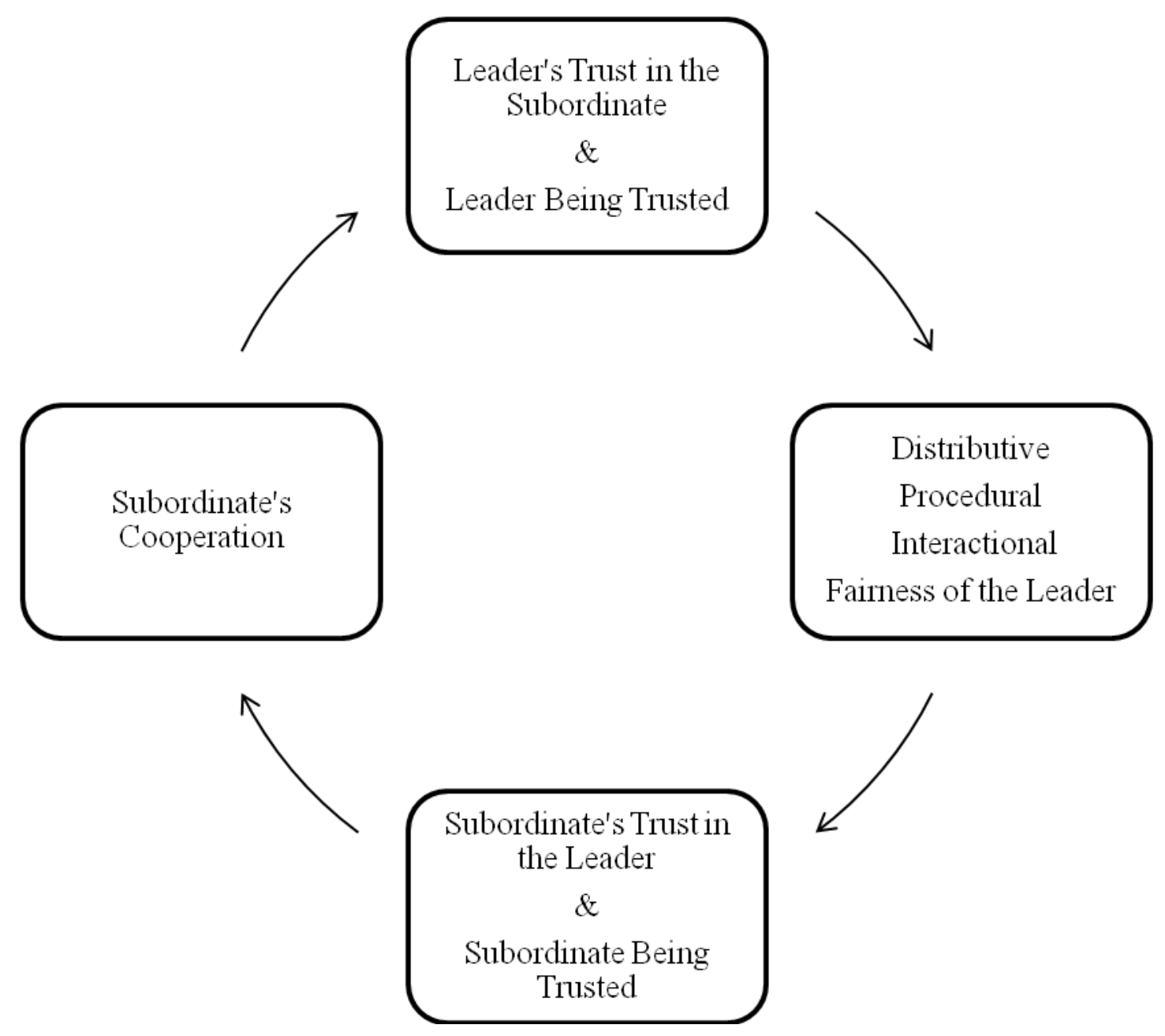


Table 1

Descriptive Statistics and Correlations Among Study Variables $(n=174)$

\begin{tabular}{|c|c|c|c|c|c|c|c|c|c|}
\hline & $\mathrm{M}$ & SD & 1 & 2 & 3 & 4 & 5 & 6 & \\
\hline 1. Helping & 4.54 & 1.59 & $(.92)$ & & & & & & \\
\hline 2. Compliance & 5.72 & 0.94 & .09 & $(.66)$ & & & & & \\
\hline 3. Performance & 6.31 & 0.81 & $.37 * * *$ & $.33 * * *$ & $(.78)$ & & & & \\
\hline 4. Trust in subordinate & 4.28 & 0.74 & $.38 * * *$ & $.27 * * *$ & $.59 * * *$ & $(.87)$ & & & \\
\hline 5. Distributive justice & 3.95 & 0.85 & .14 & .09 & $.17^{*}$ & $.23 * *$ & $(.94)$ & & \\
\hline 6. Procedural justice & 3.63 & 0.81 & .13 & $.20 * *$ & .09 & $.16^{*}$ & $.51 * * *$ & $(.90)$ & \\
\hline 7. Interactional justice & 4.08 & 0.84 & $.17^{*}$ & .13 & .10 & $.22 * *$ & $.47 * * *$ & $.74 * * *$ & $(.94)$ \\
\hline
\end{tabular}

Note. $* p<.05 ; * * p<.01, * * * p<.001$. Cronbach's alphas shown in parentheses. 
Table 2

Results of Model Comparisons

\begin{tabular}{lcccccc}
\hline Models & $\chi^{2}$ & $\mathrm{df}$ & $\Delta \chi^{2}(\mathrm{df})$ & CFI & TLI & RMSEA \\
\hline 1. Baseline model & 347.34 & 36 & - & - & - &. \\
2. No directs & 47.55 & 29 & $299.79(7) * * *$ & .94 & .93 & .06 \\
3. Model 1 & 49.15 & 28 & $1.60(1)$ & .93 & .91 & .07 \\
4. Model 2 & 48.12 & 28 & $0.57(1)$ & .94 & .92 & .08 \\
5. Model 3 & 47.20 & 28 & $0.35(1)$ & .93 & .92 & 06 \\
6. Model 4 & 46.35 & 28 & $1.20(1)$ & .94 & .92 & .06 \\
7. Model 5 & 48.54 & 28 & $0.99(1)$ & .93 & .92 & .07 \\
8. Model 6 & 44.93 & 28 & $2.62(1)$ & .94 & .93 & .06 \\
9. Only directs & 29.36 & 14 & $18.19(15)$ & .94 & .89 & .08
\end{tabular}

Note: $\mathrm{CFI}=$ comparative fit index TLI $=$ Tucker-Lewis index $;$ RMSEA $=$ root mean square error of approximation, $* * * p<.001$ 
Baseline Model $=$ only random intercepts included in the model

No directs $=$ fully mediated model

Model 1 = no directs + path from helping to interactional fairness

Model $2=$ no directs + path from helping to procedural fairness

Model 3 = no directs + path from helping to distributive fairness

Model $4=$ no directs + path from compliance to procedural fairness

Model $5=$ no directs + path from compliance to interpersonal fairness

Model $6=$ no directs + path from performance to distributive fairness 
Appendix I

Items of the Studied Variables

\section{Performance}

1. This particular employee meets the qualitative expectations of his/her work.

2. This particular employee meets the deadlines of his/her work.

3. This particular employee puts effort into his/her work.

\section{Helping}

1. This particular employee assists others in this unit with their work for the benefit of the group.

2. This particular employee volunteers to do things for this work group.

3. This particular employee volunteers to help new employees in this group.

Compliance

1. This particular employee follows work rules and instructions with extreme care.

2. This particular employee does not question the work unit's rules and instructions.

3. This particular employee follows working-hour regulations with exactness.

Leader's trust 
1. If I had my way, I wouldn't let this particular employee have any influence over issues that are important to me. (reversed)

2. I really wish I had a good way to keep an eye on this particular employee. (reversed)

3. I would be comfortable giving this particular employee a task or problem which was critical to me, even if I could not monitor his/her actions.

4. I trust this particular employee as an employee.

Distributive fairness

1. The decisions my immediate supervisor makes concerning the distribution of work are fair in relation to others doing a similar job.

2. The decisions my immediate supervisor makes concerning the distribution of work are fair in relation to my responsibilities.

3. The decisions my immediate supervisor makes concerning the distribution of work are fair in relation to my work experience.

4. The decisions my immediate supervisor makes concerning the distribution of work are fair in relation to the effort I have put in.

5. The decisions my immediate supervisor makes concerning the distribution of work are fair in relation to the quality of my work output.

6. The decisions my immediate supervisor makes concerning the distribution of work are fair in relation to the stress and strains of my job.

7. The decisions my immediate supervisor makes concerning the distribution of work are fair in relation to my competence.

Procedural Fairness

My immediate supervisor makes decisions so that... 
1. Everyone who is affected by the decision has a chance to voice his or her opinion.

2. The rules and procedures are applied consistently across people.

3. Decision-making is based on accurate and exact information.

4. Opportunities to appeal against or challenge the decisions are provided.

5. Everyone who is affected by the decision has a chance to have an influence over the decision.

6. Useful feedback regarding the decision and its implementation is provided.

7. Requests for clarification or additional information about the decision are allowed.

\section{Interactional Fairness}

1. My immediate supervisor shows concern for our rights as employees.

2. My immediate supervisor considers employees' viewpoints.

3. My immediate supervisor provides employees with timely feedback about the decision and its implementations.

4. My immediate supervisor treats employees with kindness and consideration.

5. My immediate supervisor took steps to deal with employees in a truthful manner. 
Appendix II

Confirmatory Factor Analyses

\begin{tabular}{|c|c|c|c|c|c|c|c|}
\hline Variable & $\begin{array}{l}\text { No. of } \\
\text { Factors }\end{array}$ & df & $\chi^{2}$ & $\Delta \chi^{2}(\mathrm{df})$ & CFI & TLI & $\mathrm{RM}$ \\
\hline Justice (dist. + proce. + inter.) & 1 & 160 & $1400.81 * * *$ & - & .69 & .63 & .19 \\
\hline Justice $[($ dist. + proce. $)$, inter.] & 2 & 159 & $924.33 * * *$ & $476.48(1)^{* * *}$ & .81 & .77 & .15 \\
\hline Justice [(dist. + inter.), proce.] & 2 & 159 & $1002.04 * * *$ & $398.77(1)^{* * *}$ & .79 & .75 & .16 \\
\hline Justice [dist., (proce. + inter.)] & 2 & 159 & $500.64 * * *$ & $900.17(1)^{* * *}$ & .92 & .90 & .10 \\
\hline Justice (dist.; proce., inter.) & 3 & 157 & $376.25 * * *$ & $124.39(2) * * *$ & .95 & .93 & .07 \\
\hline (trust + helping + comp. + perf. $)$ & 1 & 60 & $567.46 * * *$ & - & .62 & .51 & .22 \\
\hline$[$ (trust + helping $),($ comp. + perf. $)]$ & 2 & 59 & $417.34 * * *$ & $150.12(1)^{* * *}$ & .73 & .65 & .19 \\
\hline [(trust + perf.), (helping + comp.)] & 2 & 59 & $312.74 * * *$ & $254.72(1) * * *$ & .81 & .75 & .16 \\
\hline$[($ trust + comp. $),($ helping + perf. $)]$ & 2 & 59 & $412.08 * * *$ & $155.38(1)^{* * *}$ & .74 & .65 & .19 \\
\hline [trust; perf., (helping + comp.)] & 3 & 57 & $230.63 * * *$ & $82.11(2)^{* * *}$ & .87 & .82 & .13 \\
\hline
\end{tabular}




\begin{tabular}{|c|c|c|c|c|c|c|c|}
\hline [trust; comp., (helping + perf.)] & 3 & 57 & $340.81 * * *$ & $28.07(2) * * *$ & .79 & .71 & .17 \\
\hline [comp; perf., (trust + helping)] & 3 & 57 & $357.36 * * *$ & $44.62(2) * * *$ & .78 & .69 & .18 \\
\hline [trust; helping, (comp. + perf.)] & 3 & 57 & $169.90 * * *$ & $142.84(2) * * *$ & .91 & .88 & .11 \\
\hline [helping; perf.,(trust + comp.)] & 3 & 57 & $182.49 * * *$ & $130.25(2) * * *$ & .91 & .87 & .11 \\
\hline [comp.; helping., (trust +perf.)] & 3 & 57 & $194.94 * * *$ & $117.80(2)^{* * *}$ & .89 & .86 & .12 \\
\hline trust; helping; comp., perf. & 4 & 54 & $107.88 * * *$ & $62.02(3) * * *$ & .96 & .92 & .07 \\
\hline
\end{tabular}

Note: $\mathrm{CFI}=$ comparative fit index; TLI = Tucker-Lewis index; RMSEA = root mean square error of approximation; dist. = distributive justice; proce.$=$ procedural justice inter. $=$ interactional justice; helping $=$ helping OCB $;$ comp.$=$ compliance OCB, perf. $=$ performance. Variables that are presented in parentheses are tested as a single factor. $* * * p<.001$. The two-level structure of data was not taken into account. 